GSA Data Repository 2015050

1 Supplementary Information to "Global perturbation of the carbon

2 cycle at the onset of the Miocene climatic optimum"

3

Our study is based on lower to middle Miocene marine sediments recovered at IODP Site U1337 $\left(3^{\circ} 50.009^{\prime} \mathrm{N}, 123^{\circ} 12.352^{\prime} \mathrm{W} ; 4200 \mathrm{~m}\right.$ water depth) in the eastern equatorial Pacific Ocean during the Pacific Equatorial Age Transect (PEAT) Expedition 321 (Supplementary Fig. S1). Detailed site location, core recovery and

8 lithological descriptions are provided in Pälike et al. (2010). This work extends

9 middle Miocene benthic foraminiferal isotope studies in Site U1337 (Tian et al., 2013) and Site U1338 (Holbourn et al., 2014).

Sampling strategy composite sequence (shipboard splice) from Holes U1337A, U1337C and U1137D (334.46 - 440.43 meters composite depth). Samples were oven dried at $40^{\circ} \mathrm{C}$, washed over a $63 \mu \mathrm{m}$ sieve, then oven dried at $40^{\circ} \mathrm{C}$ on a sheet of filter paper.

\title{
Astronomically-tuned chronology
}

Astronomical tuning and calculation of sedimentation rates were performed with AnalySeries 2.0.4.2 (Paillard et al., 1996). We correlated $\delta^{18} \mathrm{O}$ minima to

$21 \mathrm{ET}+0.2 \mathrm{P}$ maxima, following a minimal tuning strategy to preserve original spectral

22 characteristics. The benthic isotope data set from Site U1337 is plotted against

23 composite depth and against age in Supplementary Fig. S2. Age tie points between

24 the $\delta^{18} \mathrm{O}$ series and the ETP target (Laskar et al., 2004) are shown in Supplementary 
25 Fig. S2 and Supplementary Table S1. The average sedimentation rate is $\sim 2 \mathrm{~cm} \mathrm{kyr}^{-1}$, corresponding to an average chronological resolution of $\sim 5 \mathrm{kyr}$. spectral characteristics are retained following the tuning procedure. We note that the short eccentricity cycle $(100 \mathrm{kyr})$ is prominently imprinted in the $\delta^{18} \mathrm{O}$ and $\delta^{13} \mathrm{C}$ records (Supplementary Figs. S2-S3). Superimposed on higher frequency variations, the 400 kyr eccentricity cycle is additionally encoded in the $\delta^{13} \mathrm{C}$ record (Supplementary Fig. S3). The detection of the 100 and 400 kyr eccentricity cycles in the $\delta^{13} \mathrm{C}$ series supports the age model, based on independent tuning of the $\delta^{18} \mathrm{O}$ series. indicates that the independent age models are overall compatible (Supplementary Fig. U1337 are identified in Site 1090, further supporting the global nature of these events. The apparent temporal offset at the onset of the $\delta^{18} \mathrm{O}$ and $\delta^{13} \mathrm{C}$ decreases is most likely due to the incompleteness of the Site 1090 over this interval.

\section{Benthic foraminiferal and bulk carbonate $\delta^{18} \mathrm{O}$ and $\delta^{13} \mathrm{C}$}

Between 17.2 and 15.5 Ma, benthic foraminiferal and bulk carbonate $\delta^{18} \mathrm{O}$ have means of $1.33 \%$ and $-0.25 \%$ with standard deviation of $0.30 \%$, and $0.29 \%$,

46 respectively. Benthic and bulk carbonate $\delta^{13} \mathrm{C}$ have means of $1.13 \%$ and $1.94 \%$

47 with standard deviation of 0.33 and $0.29 \%$, respectively. The offset in mean values

48 reflects the different origins of the source materials, as the bulk carbonate (lighter 
$49 \delta^{18} \mathrm{O}$, heavier $\delta^{13} \mathrm{C}$ ) represents a near surface signal, primarily based on calcareous

50 nannofossils derived from surface-dwelling algae. The benthic and bulk carbonate

$51 \delta^{18} \mathrm{O}$ and $\delta^{13} \mathrm{C}$ records show a marked co-variance in the $100 \mathrm{kyr}$ eccentricity band

52 from 17.2 to $15.5 \mathrm{Ma}$ (Fig. 2, Supplementary Figs. S2-S3). This is particularly

53 striking for the prominent $\delta^{18} \mathrm{O}$ minima at 16 and $15.6 \mathrm{Ma}$, which coincide with sharp

$54 \quad \delta^{13} \mathrm{C}$ minima.

55 We checked the abundance, distribution and preservation of calcareous

56 nannofossils in selected samples with different carbonate contents, using a scanning

57 electron microscope. We found that abundance decreased slightly with carbonate

58 content, but that assemblage composition (size and taxonomic groups) and

59 preservation did not differ markedly. Thus, we concluded that the bulk carbonate

60 isotope signals are not primarily influenced by changes in assemblage composition

61 due to selective dissolution.

62

\section{REFERENCES}

64 Billups, K., Channell, J.E.T., and Zachos, J., 2002, Late Oligocene to early Miocene geochronology and paleoceanography from the sub-Antarctic South Atlantic:

67 Billups, K., Pälike, H., Channell, J.E.T., Zachos, J.C., and Shackleton, N.J., 2004, 68 Astronomic calibration of the late Oligocene through early Miocene geomagnetic 69 polarity time scale: Earth and Planetary Science Letters, v. 224, p. 33-44, doi:10.1016/j.epsl.2004.05.004.

71 Holbourn, A.E., Kuhnt, W., Lyle, M.W., Schneider, L., Romero, O., and Andersen. N., 2014, Middle Miocene climate cooling linked to intensification of eastern equatorial Pacific upwelling: Geology, v. 42, p. 19-22, doi:10.1130/G34890.1. 
Laskar, J., Robutel, P., Joutel, F., Gastineau, M., Correia, A., and Levrard, B., 2004,

A long-term numerical solution for the insolation quantities of the Earth: Astronomy and Astrophysics, v. 428, p. 261-285, doi:10.1051/00046361:20041335.

Paillard, D., Labeyrie, L., and Yiou, P., 1996, Macintosh program performs timeseries analysis: EOS Transactions AGU, v. 77, p. 379.

Pälike, H., Lyle, M.W., Nishi, H., Raffi, I., Gamage, K., Klaus, A., and the Expedition 320/321 Scientists, 2010, Proceedings of the Integrated Ocean Drilling Program, 320/321: Tokyo, Integrated Ocean Drilling Program Management International, Inc., doi:10.2204/iodp.proc.320321.109.2010.

Tian, J., Yang, M., Lyle, M.W., Wilkens, R., and Schackford, J.K., 2013, Obliquity and long eccentricity pacing of the Middle Miocene climate transition: Geochemistry, Geophysics, Geosystems, v. 14, p. 1740-1755, doi:10.1002/ggge.20108.

Woodruff, F., and Savin, S., 1991, Mid-Miocene isotope stratigraphy in the deep sea: high resolution correlations, paleoclimatic cycles, and sediment preservation: Paleoceanography, v. 6, p. 755-806.

\section{CAPTIONS FOR SUPPLEMENTARY FIGURES AND TABLE}

Supplementary Figure 1. Map showing the present day location of IODP Site U1337 in the eastern equatorial Pacific $\left(3^{\circ} 50.009^{\prime} \mathrm{N}, 123^{\circ} 12.352^{\prime} \mathrm{W} ; 4200 \mathrm{~m}\right.$ water depth). Site U1337 was located SW of its present position, within $\pm 2^{\circ}$ of the Equator between 8 and $24 \mathrm{Ma}$ (Pälike et al., 2010). 
Supplementary Figure 2. (a) U1337 benthic $\delta^{18} \mathrm{O}$ versus meters composite depth

\section{0}

101

102

103

104

105

106

107

108

109

110 Supplementary Figure 4. Comparison of U1337 benthic $\delta^{18} \mathrm{O}$ and $\delta^{13} \mathrm{C}$ with

111 independently age calibrated records from ODP Site 1090, subantarctic Atlantic

112 Ocean (Billups et al., 2002; 2004). (a) Benthic $\delta^{13} \mathrm{C}$ from ODP Site 1090. (b) Benthic

$113 \delta \delta^{13} \mathrm{C}$ from IODP Site U1337. (c) Benthic $\delta^{18} \mathrm{O}$ from ODP Site 1090. (d) Benthic $\delta^{18} \mathrm{O}$

114 from IODP Site U1337. PDB: PeeDee Belemnite, MCO: Miocene Climatic Optimum.

115 Purple crosses mark prominent correlative features. Lilac shading marks sharp $\delta^{18} \mathrm{O}$

116 decreases coincident with negative shift in $\delta^{13} \mathrm{C}$ (shaded orange).

117

118 Supplementary Table 1. Age control points used to derive astronomically tuned

119 timescale in IODP Site U1337. 


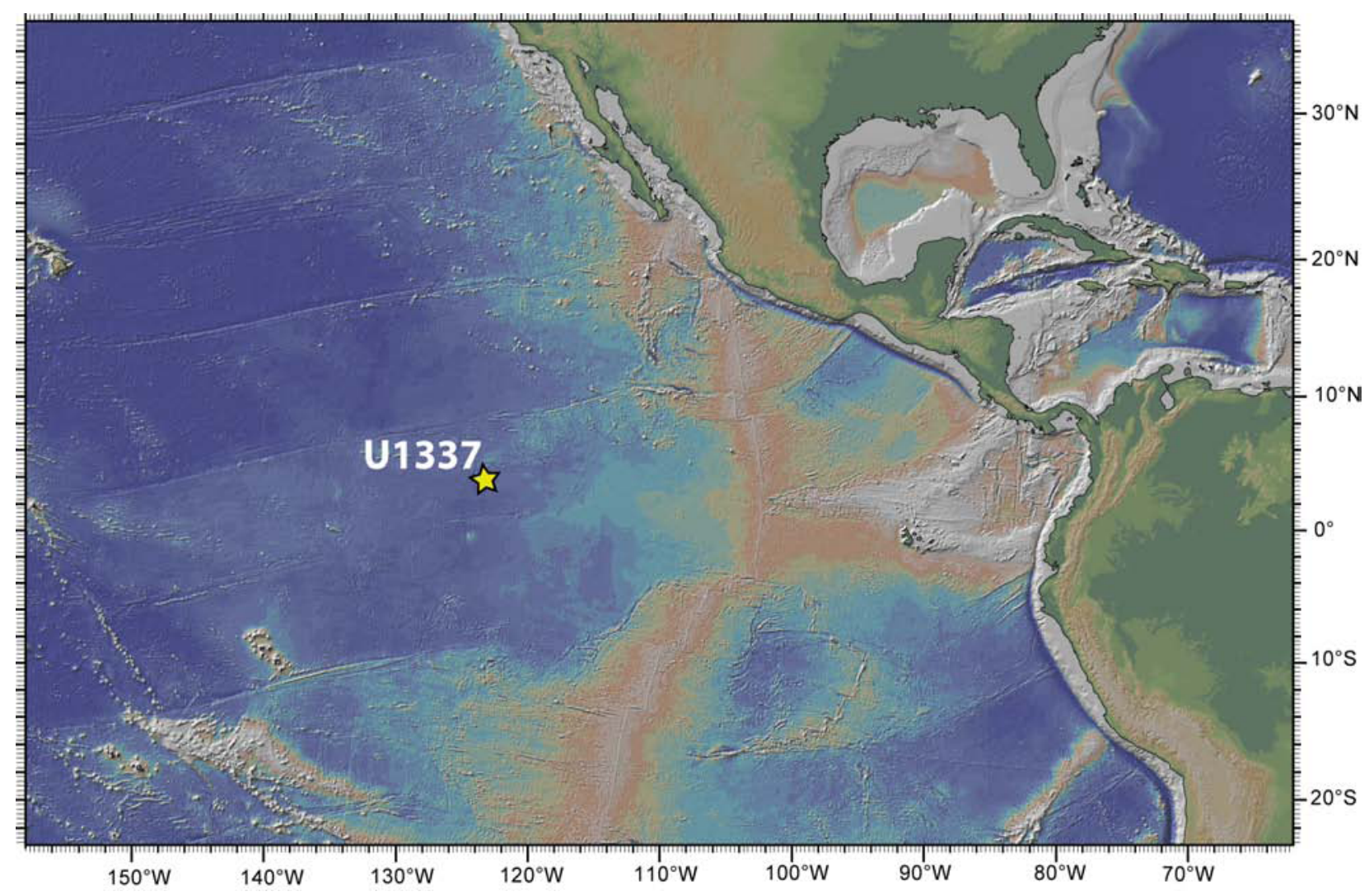

Supplementary Figure S1 



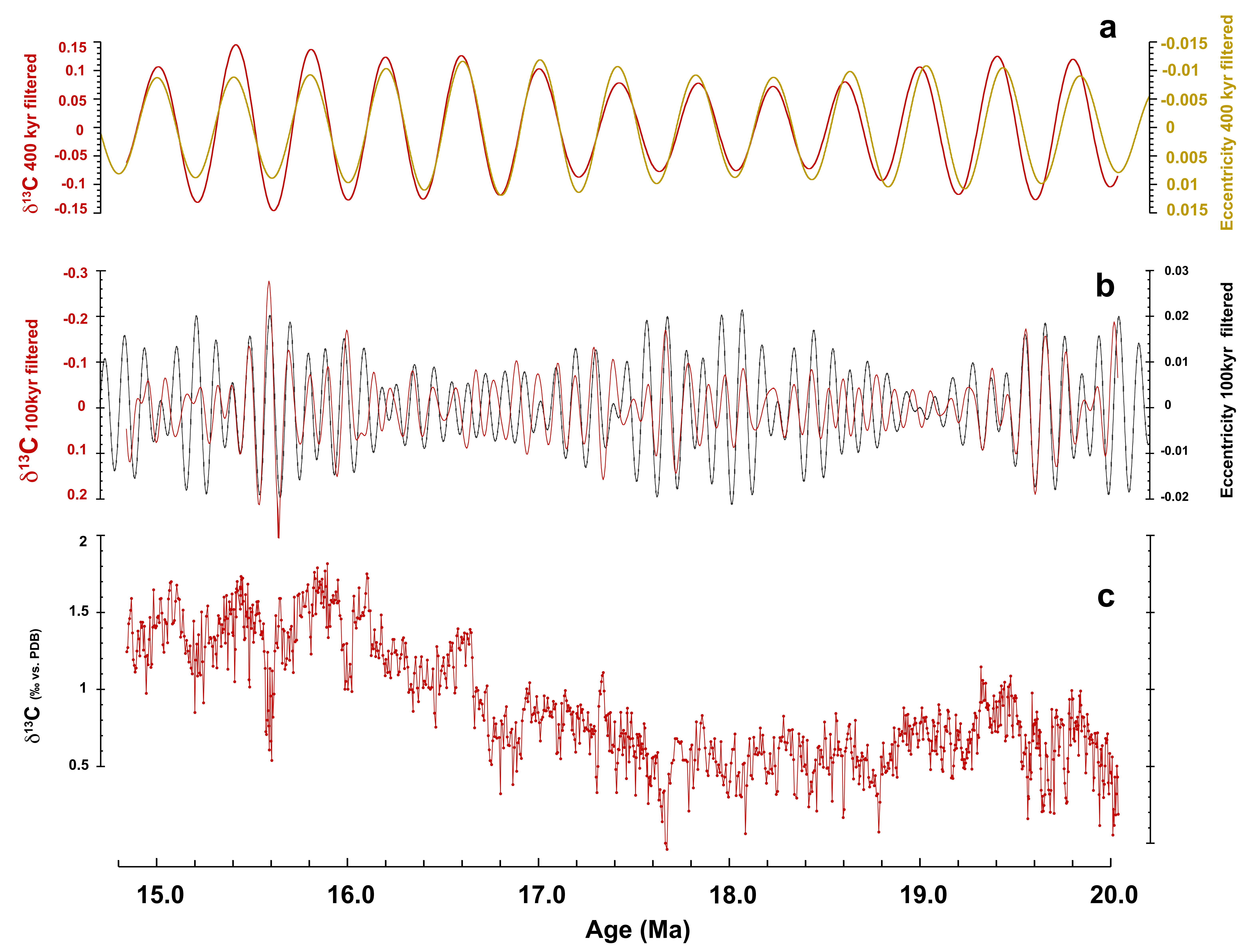

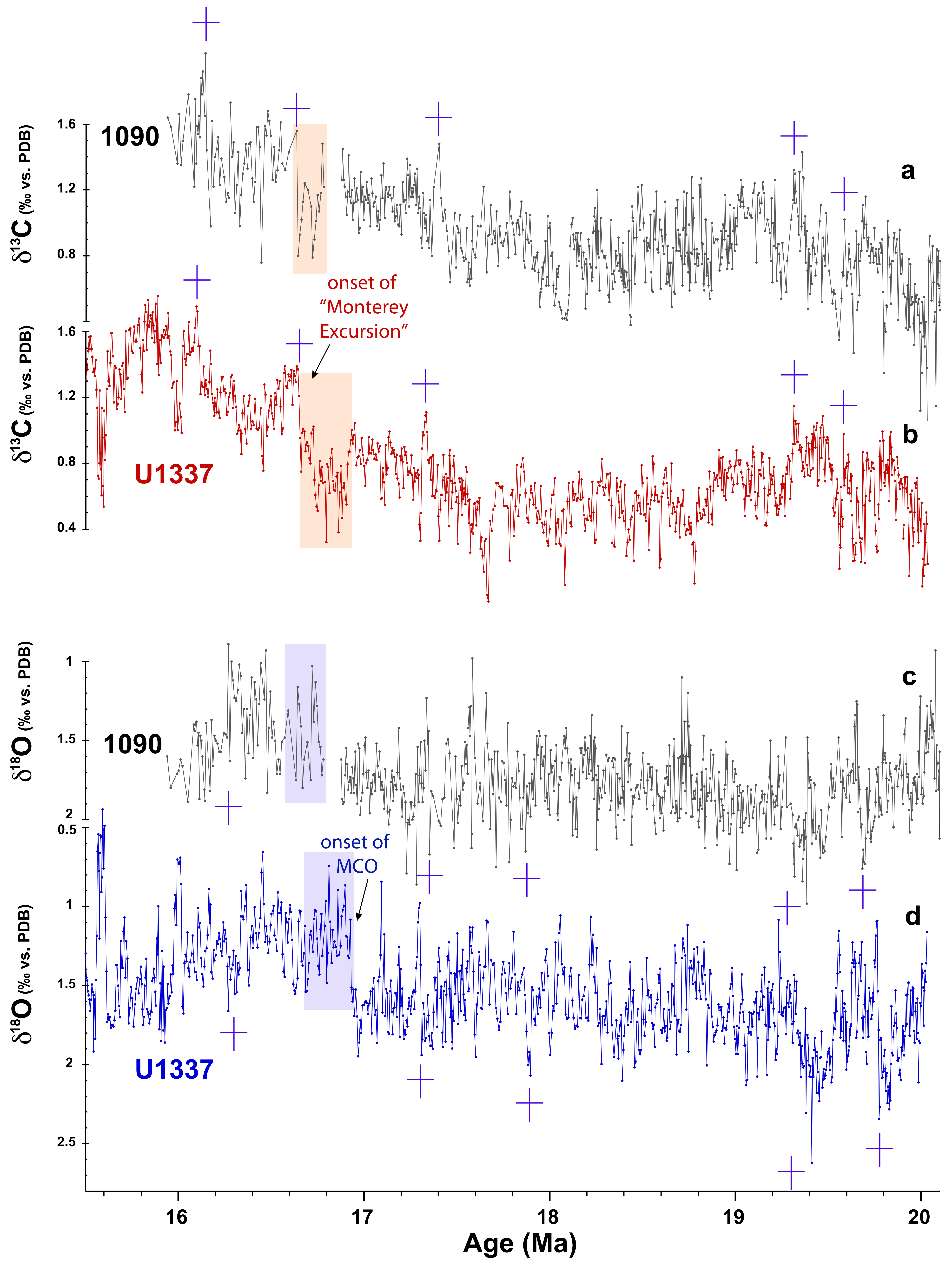

Supplementary Figure S4 
Supplementary Table 1

\begin{tabular}{|c|c|}
\hline Depth (mcd) & Age (ka) \\
\hline 336.66 & 14949 \\
\hline 339.35 & 15080 \\
\hline 339.96 & 15119 \\
\hline 341.17 & 15194 \\
\hline 341.97 & 15234 \\
\hline 342.72 & 15286 \\
\hline 343.72 & 15325 \\
\hline 345.91 & 15402 \\
\hline 348.52 & 15479 \\
\hline 350.69 & 15569 \\
\hline 351.55 & 15594 \\
\hline 354.15 & 15721 \\
\hline 355.31 & 15799 \\
\hline 357.62 & 15892 \\
\hline 359.9 & 16010 \\
\hline 365.79 & 16341 \\
\hline 367.33 & 16456 \\
\hline 373.5 & 16812 \\
\hline 374.89 & 16898 \\
\hline 375.41 & 16927 \\
\hline 378.21 & 17095 \\
\hline 380.11 & 17189 \\
\hline 382.46 & 17301 \\
\hline 385.76 & 17455 \\
\hline 389.25 & 17585 \\
\hline 390.58 & 17661 \\
\hline 391.35 & 17727 \\
\hline 393.36 & 17884 \\
\hline 394.85 & 17983 \\
\hline 395.95 & 18058 \\
\hline 397.24 & 18150 \\
\hline 400.24 & 18343 \\
\hline 401.82 & 18434 \\
\hline 403.32 & 18523 \\
\hline 407.32 & 18717 \\
\hline 409.25 & 18832 \\
\hline 413.11 & 19035 \\
\hline 416.46 & 19158 \\
\hline 418.39 & 19234 \\
\hline 426.42 & 19558 \\
\hline 429.24 & 19632 \\
\hline 432.51 & 19764 \\
\hline 435.04 & 19841 \\
\hline 437.61 & 19934 \\
\hline 439.73 & 20008 \\
\hline & \\
\hline
\end{tabular}

